\title{
Investigation and Development Technology of Methane Emission Reduction on Exhaust Gas Emitted from Dual Fuel Diesel Engine; a Literature Review
}

\author{
Betty Ariani*, I Made Ariana \\ Departement of Marine Engineering, Institut Teknologi Sepuluh Nopember, Surabaya, Indonesia \\ a.betty.ariani@gmail.com \\ *corresponding author
}

Keywords: Combustion, dual fuel, exhaust gases, slipped methane, natural gas, post treatment.

Abstract: Global warming, climate change, regulation and limitation on emission has become attractiveness factor that pushing many researchers to build method for reducing emission. As we know that global warming and climate change make a big problem for human life. Dual fuel engine (DF) which has combining two characteristics of fuel between low and high reactivity fuel is represented as one of solution. DF diesel - natural gas consists of diesel oil high reactivity fuel as pilot and natural gas as main fuel, natural gas (NG) has many benefits such as low price, low emission, clean alternative fuel, abundant resources and high thermal efficiency. But in fact, DF concept has weakness factor, methane slip or unburned methane have been criticized as one of greenhouse gases. In many researches find that it has global warming potential higher than carbon dioxide. This paper presents a literature review on the investigation and development technology of methane emission reduction on DF. Some technology and strategy on reducing methane slip are devided into three basic strategy, they are redesign engine, optimization on combustion process and after treatment technology of exhaust gases. Some research opportunities in the field of both technology for reducing unburn methane will be discussed and could be addressed for future research.

\section{Introduction}

For a few years, there are some important issue on development industry, environmental and high price of oil which are driving to make diversify on fuel market. As we know that now many activity are depend on fossil fuel eventhough burning fossil fuel increasing green house gases which can cause a change in the climate. So in summary of [1] there are two great interest factor on developing alternative fuel in transportasion both fossil and renewable energy, they are change of climate and high price of oil..

The dual fuel engine (DF) is a concept which combining two characteristic of the fuel, low and high reactivity fuel. Interested in natural gas for replacing diesel fuel in compression ignition engines have substantially increased in recent years. Using natural gas (NG) as low reactivity fuel as main fuel can reduce cost operation, lower exhaust gases emission than diesel. In particular the 
combination of two characteristic fuel may allow for optimal operation and high thermal efficiency. The flexibility of this engine is also high because it can be operated in two modes, diesel mode can be applicated immeditialy if NG are not available.

The scenario of DF diesel - NG is in a lean combustion, allow the gaseous fuel well mixed with the intake air of the engine outside the cylinder. When the mixture become homogeneous it inducted into the cylinder. But this scenario will make higher unburned methane and lower thermal efficiency [2]. Diesel fuel as a high reactivity is injected into the cylinder upstream of the intake valve. In the gas fumigated CI engine, Nox and PM emissions was lower than conventional diesel but vice versa on $\mathrm{CO}$ and $\mathrm{HC}$ emissions [3]. By simulation the researcher on [4] invented that at low condition $27-$ $35 \%$ methane was not participating on the process of combustion., in main combustion there was 43 $-53 \%$ of the methane fumigated into the intake mixture, $17-29 \%$ was consumed on oxidation process (post combustion). When methane emitted without participating on combustion has release in to the air, we named it slipped methane, it can cause photochemical smog and disease.

Methane is one of green house gases besides CO2, NOx and fluorinated gases. GHG is a heat trap which has contribution in making a global warming and climate change. On [5] says that methane has an unique characteristic, it has life time much shorter than $\mathrm{CO} 2$ but more efficient for trapping radiation. So it is not excessive thing if this future research focus on reducing methane slip. Methane is also an asphyxiant which is in high concentrations may displace the oxygen supply for our breathing especialy in confined space. Suffocation and loss of consciousness are side effect of oxygen lacking. It can also cause many problem in our health likes headache, dizziness, weakness, nausea, vomiting and loss of our coordination.

Development on industrial and high attention to the impact of emissions led to emission regulation more tighter.

However, unfavorable conditions for the environment caused by human activities should be suppressed by the rules which is agreed and obeyed together. Regulation and limitation about emission will grow up as the importance of creating a better living for our next generation in the future. This table show the regulation as limitation on emission Tier on USA, Europe and Japan. 
Table 1: Limitation on Emission Tier on USA, EU \& Japan.

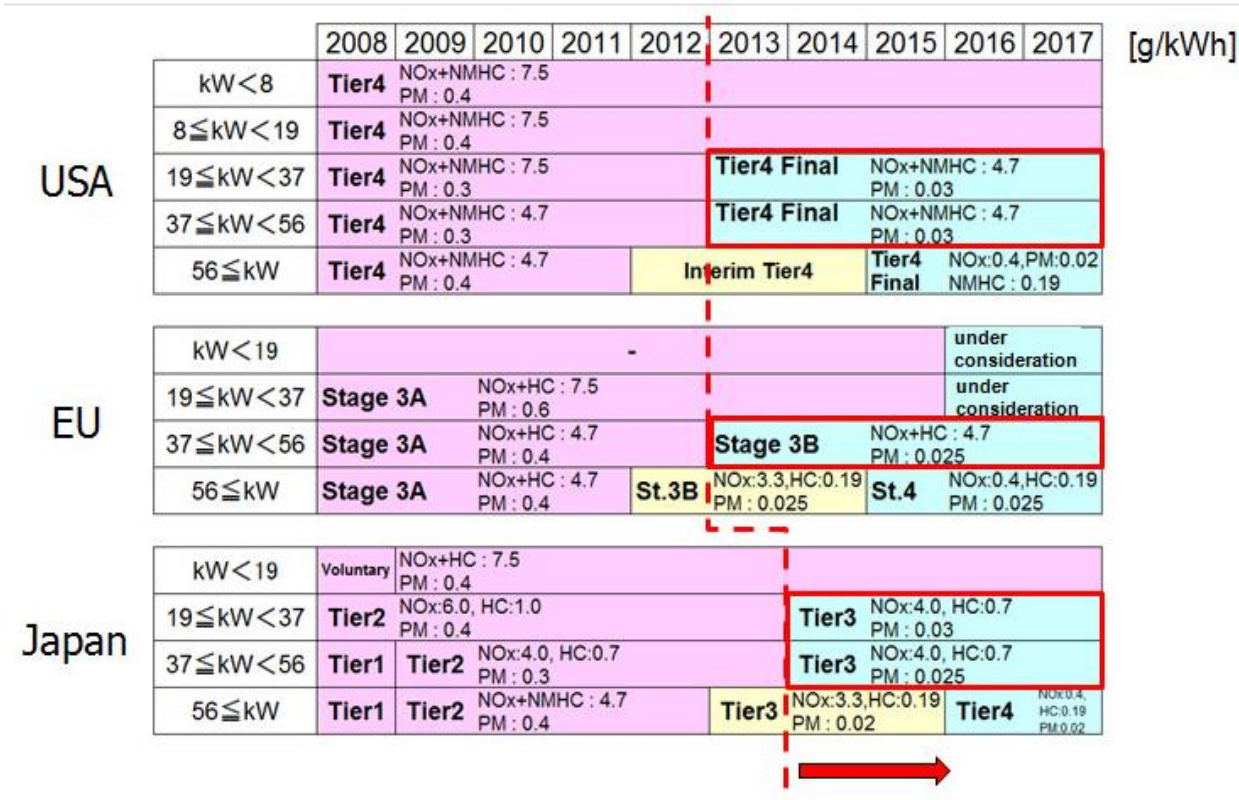

As see on the table above, the regulation becoming tighter and tighter. It is without doubt that development on technology and strategy to comply with is a difficult thing, but it is in our hands and depend on our desire to make it happen. We must exert our effort to build technology and strategy to make a real change.

Slipped methane or unburned hydrocarbon (UHC) become a problem since gases was used as a fuel. There are three main things as driving factor for the methane slip. According to [1] there are crevice losses, adsorption and quenching.

Crevice losses, in terms of engine, the dead volume which formed due to the gap in the cylinder of the unit such as the gasket area between cylinder head and the liner cylinder, area between the piston land and the cylinder liner and area behind the anti polishing ring. Conditions in this are narrow, cold, and of course are unfavorable for flame propagations When compression, mixture of the gas enter to the crevices and does not participate in combustion process when the gas ekspansion return to the burning area the temperature has gone down and the pressure in the cylinder drops. So it does not burn but just flow with exhaust gas.

Adsorption, at high pressure partially of gas fuel adsorbed into layer on the cylinder wall and retained in the combustion chamber. After ekspansion the pressure drops and it return to burning area without participating on combustion.

Quenching, if A/F ratio is less appropriate, it will become one of factor which drive incomplete combustion or engine on low load condition, low temperature and pressure makes flame quenches before it reaches cylinder wall and some hydrocarbon in the boundary layer may escape combustion.

\section{Methodology}

This paper was a literature review, the process of writing on this literature review was divided into several steps and stages. The first stage was collection some papers from reputable sources randomly, the papers had to related with emissions and performance on dual fuel engines. The topic would be discussed was about how technology developed to reduce emissions on dual fuel engine. Some paper were obtained through science direct.,proquest and springer with the key word methane emission , unburn methane and technology on dual fuel engine. The second stage was selecting the two topic of some papers which related with reducing methane emission, they were engine design and controlling 
operating parameters. On technology to reduce unburn methane was devided into three main methode, technology on combustion mode (TCM), engine design strategy (EDS) and post treatment of exhaust gases(PT).

Discussion about research methods and found the challenge then analyzed many directions of research that can be done in the future, especially focus on optimization technology advance combustion on dual fuel marine engine for reducing slipped methane

\section{Result}

These are some effort to combat the high slipped methane (UHC) value from many research. The researcher have implemented various strategies. Some technology are devided by three basic field they are technology on combustion mode (TCM), engine design strategy (EDS) and post treatment of exhaust gases (PT).

The graphic below shows us for about twenty four paper research we have read and review. They divided into three group paper based on research area and solution method.

On TCM , technology combustion methode as reported in the literature consists of control parameter on fuel injection timing, amount of quantity pilot injection, intake manifold temperature and multiple injection. It takes $52 \%$ of paper research, post treatment which consists of exhaust gas recirculating, methane oxidation catalyst and using MPC for controlling air path. Take less procentage is engine design strategy, redesign piston and ring, using gas permeation membrane, and redesign cylinder head.

Table 2: Solution method.

\begin{tabular}{|c|c|c|}
\hline Author & Area & Solution Methode \\
\hline$[1][2][7][19]$ & TCM & Fuel Injection Timing \\
\hline$[4][13][20][22][23][24]$ & TCM & Pilot Fuel Quantity \\
\hline$[8][14][18][22]$ & TCM & Intake Manifold Temperature \\
\hline$[8][15][17]$ & PT & Exhaust Gas Recirculation \\
\hline$[3][16]$ & TCM & Multiple injection \\
\hline$[12]$ & EDS & Gas permeation membrane \\
\hline$[9]$ & EDS & Incylinder air motion, swirl and tumble \\
\hline$[1]$ & PT & Methane oxidation catalyst \\
\hline$[9]$ & EDS & Redesign piston and ring \\
\hline$[1]$ & EDS & Redesign of cylinder head \\
\hline$[21]$ & PT & Air path control using MPC \\
\hline
\end{tabular}




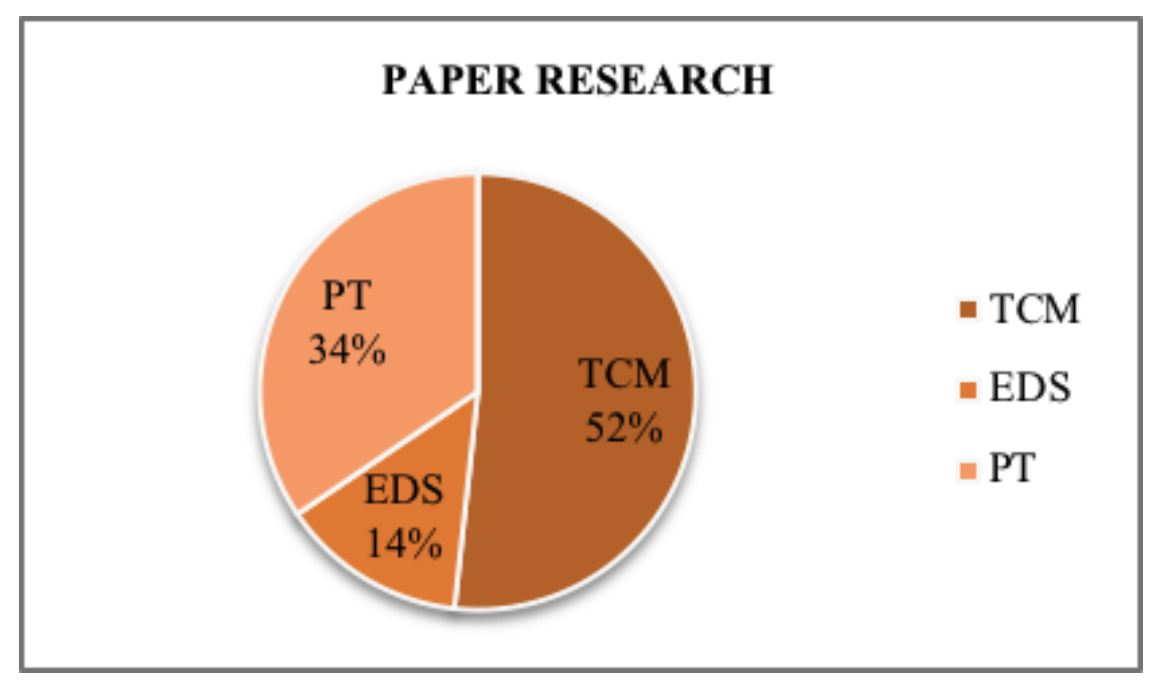

Figure 1: Graphic of three group paper research.

\section{Discussion}

The researcher on TCM (technical combustion methode) area generally discuss about how to improve combustion process more complete, faster and perfect because a perfect combustion process will reduce unburn methane significantly. For this reason, several author report a reduction in unburned hydrocarbons when advancing the injection timing [1], [2], [19] [22]. But the optimum injection timing and duration which lead to emission reduction is dependent on load and rpm and it consider as optimization problem inthe future. [7] research on the methodology was applied to obtain a more profound understanding of the relationship between injection timing and combustion phasing. The injection strategy divided into early, medium and late injection timing. On [3] researcher also explained that reducing slipped methane (UHC) using multy injection methode has best result in early main injection. It is a promising idea on dual fuel engine (DF) development strategy on reducing slipped methane.

Other methodes also presented by the researcher on [13][20][22][23][24] throught variation on diesel substitution rate and amount of pilot injection. UHC and $\mathrm{CO}$ will increase if diesel substitution rate increase and amount of pilot injection decrease. Increased inlet temperature to reducing slipped methane has investigated by [8] [14] [18] [22] but new problem has rises in this methode, knocking and preignition especially at high load condition. So the root cause of preignition and how to minimalizing occurance of knocking must be found on the future research.

On post treatment we have exhaust gases recirculation system, air path and oxidation catalyst. EGR was rises because of considering that it is difficult to comply with such strict emission regulation. We have to know that characteristic of emission was unique and some time controversial result such as Nox and UHC, decrease NOx will inevitably lead to UHC and vice versa. The advantage of EGR system are reaching ideal conditions (stoichiometric), making condition close to complete combustion, minimizing throotling loss, and cost eficient. Efficiency cost of after treatment system throught using three way catalist. EGR system could accomodate reducing both Nox and UHC because of it would reburning of the unburn methane. The author [8] [15] [17] have proposed a methode to reduce slipped methane using exhaust gas recirculating (EGR) system. Researcher on [8] has investigated the effect of the intake gas compositions on the combustion characteristic of diesel engine operated in $\mathrm{C}$-EGR system. As a result the increase of methane $(\mathrm{CH} 4)$ concentration and the decrease of oxygen $(\mathrm{O} 2)$ concentration have trade off effects between Nox and UHC reduction. So the challenge in the future research is investigation for the measure to improve UHC emissions in low load with keeping NOx emission. 
In DF engine, piston top land volume was the main source of $\mathrm{HC}$ emission. In order to reducing it researcher on [9] has proposed a redesign of the piston ring land. It resulted 50\% reduction in top land volume. A 50\% reduction in topland volume would translate into a reduction in HC emissions of approximially 25\%. On EDS methode based on experimental in research [9], in order to create different in cylinder air flows, they using a fully variable valve train combining with high swirl cylinder head. The effect of these combination between air flows, swirl and tumble at high $\lambda$ was affected on combustion, emission and transfer of heat in dual fuel engine. They also invented that swirl increased the oxidation of UHC returning from crevice so it will have positive effect on reducing slipped methane.

Based on [4] all about 27 - 35\% methane emitted the engine without participating on the combustion process. The slipped methane (UHC) phenomenon was due to the fact that there were many factors which affected on combustion process in DF, such as the premixed mixture between air and fuel was too lean, so it cannot support well the propagation of the turbulent flame, focused on amount of pilot fuel which initiated the propagation was one of approaching method to enhance the combustion and minimizing the methane emission.

\section{Conclusions}

From the analysis of paper selected, it can be concluded several research opportunities in the future. TCM, Technology on Combustion modes of dual fuel engine need optimization in design, operation and injection strategies. The combustion of methane in a NG - Diesel dual fuel have to conduct with post combustion. By continuous development of the combustion chamber technology to improve the combustion process and using oxidation catalyst we can get high efficiency in reduction of methane emission. Combining only one methode or more than it will decrease UHC significanly. But remember to focus not only on slipped methane, but also on NOx, CO and others emission. Using strategy and technology which is acomodated reducing of all emission to comply with regulation and high performance. Correcting gas admission valve timing, using of pre chamber technology and optimizing combustion by homogeneous mixture air fuel or using selective catalyst reduction are methode which can be chosen or combined to get best result on engine performance and emissions

\section{References}

[1] Frederick Koniggson, On Combustion in the CNG - Diesel Dual Fuel Engine,

[2] Korankianitis T, Namasiyayam AM, Crookes RJ, Natural Gas Fueled Spark Ignition (SI) and Compression Ignition (CI) engine Performance and Emissions, Prog Energy Combust 2011:37:89 - 112

[3] Yu Lie ,Hailin Lia, Hongsheng,Yong zhilic, Ming fayaoc, Numerical Simulation of Combustion and Unburnt Product in Dual Fuel Compression Ignition Engines with Multiple Injection, Applied Energy 2017

[4] YU lia, Hailin Lia, Hongsheng Guob, Yongzhi Lic, Mingfa Yao, A numerical investigation on methane combustion and emissions from natural gas-diesel dual fuel engine using CFD model

[5] United States Environmental Protection Agency, overview of Green House Effect, https://www.epa.gov, 19 Januari 2017

[6] https://www.yanmar.com/global/technology/technical_review/2015

[7] Maximilian Malin, Lucas Eder, Gerhard Pirker, Christhoph Redtenbacher, Andreas Wimmer, Daisuke Tsuru, Koji Takasaki, A Comprehensive Methodology for the Development of Dual Fuel Combustion Concepts for Marine Applications., ISME Tokyo Japan 2017.

[8] Yoshifuru Nitta, Yoichi Niki, Koichi Hirata, Yudai Hamasaki, Effect of the Combustion Characteristic of Diesel Engine by The Intake of Exhaust Gas from Gas Engine, National institute of Maritime, port and Aviation Technology, ASME Japan 2017

[9] Frederick Konigston, Henrik dembinski, Hans Erik Angstrom, The influence of - in cylinder flows on emissions and heat transfer from methane - diesel dual fuel, SAE International journal of Engines 6 (4) 2013

[10] Natural Gas Vehicles for America. Oil price volatility. [accessed February 2017]. 
[11] Qu ping, Yu Hongliang, Zhang Fengbo, Zhao Wenjuan, Li Feng, Wan Jialin, Characteristic Analysis in Combustion process of Marine Dual Fuel Engine, Applied Mechanic and Material Vol 727 - 728 pp 465 - 468

[12] Hirohi Tajima, Daisuke Tsuru, Reduction of Methane Slip from Gas engine by $\mathrm{O}_{2}$ Concentration Control using Gas Permeation Membrane, SAE Technical Paper 2013 -01-2618

[13] Nafis Ahmad I, M.K Gajendra Babu, Ramesh, Experimental Investigations of Different Parameter Affecting the Performance of a CNG - Diesel Dual Fuel Engine, SAE 2005-01-3767,2005

[14] Frederick Koniggston, Per stalhalmar, Hans Erik Angstrom, the Characterization and Potential of Dual Fuel in a Modern Diesel Engine, SAE Technical Paper 2011-01-2223

[15] Selim,mye, Effect of Exhaust Gas Recirculation on Some CombustionCharacteristic of Dual Fuel Engine, Energy Convers Manage 2003:44 707-21

[16] Kyle A Hodges, Strategies for reduced unburned hydrocarbon and carbon monoxide emissions in diesel propane dual fuel low temperature combustion. By APPROVAL PAGE

[17] Zhou L, Liu YF, Sun L, Hou HX, Zeng K, Huang ZH. Effect of hot exhaust gas recirculation on the combustion characteristics and particles emissions of a pilot ignited natural gas engine. Society of Automotive Engineers (SAE) technical paper 2013-01-1341

[18] Papagiannakis RG. Study of air inlet preheating and EGR impacts for improving the operation of compression ignition engine running under dual fuel mode. Energy Convers Manage 2013;68:40-53.

[19] Sun L, Liu YF, Zeng K. Combustion performance and stability in dual fuel engine with different pilot diesel injection timing. J Xi'an Jiaotong Univ 2014;48 (7):29- 33.

[20] Liu J, Yang F, Wang H, Ouyang MG, Hao SG. Effects of pilot fuel quantity on the emissions characteristics of a CNG/diesel dual fuel engine with optimized pilot injection timing. Appl Energy 2013;110:201-6.

[21] Esteban R Gelso, Johan Dahl, Diesel Engine Control With Exhaust Aftertreatment Constraint, IFAC Papers Online pp 8921-8926 2017

[22] G.A Karim, Z.Liu and W.Zones, Exhaust Emissions from Dual Fuel Engines at Light Load, SAE 932822,1993

[23] B.B.Sahoo, N Sahoo and UK Saha, Effect of Engine Parameter and Type of Gasesous Fuel on the Performance of Dual Fuel Gas Diesel Engines, a Critical Review, Renewable and Sustainable Energy Reviews Vol 13,2009

[24] Z lin and W.Su, A Study on The Determination of The Amount of Pilot Injection and Rich and Lean Boundries of the Premixed CNG/Diesel Dual Fuel Engine, SAE 2003-01-0765,2003

[25] Inge Saanum, Marie Bysveen, Per Tunestal, Bengt Johannson, Lean Burn Versus Stochiometric Operation with EGR and 3 Way Catalyst of an Engine Fueled with Natural Gas and Hydrogen Enriched Natural Gas, SAE 2007 $-01-0015,2007$

[26] Derek R Johnson, Robert Heltzel, Andrew C Nix, Nigel Clark, Mahdi Darzi, Green House Gas Emissions and Fuel Efficiency of In Use High Horse Power Diesel, Dual Fuel, and Natural Gas Engines for Unconventional well Development

[27] Vebrennungstagung, Toward Modelling of Multiple Combustion modes: Dual Fuel Concept and Formulation, ETH Zurich 2015

[28] John platt, What is Methane and Why you should care, https://www.mnn.com ,11 may 2017 